\title{
THE CONTEMPORARY TRENDS IN INTEGRATION OF MANAGEMENT SYSTEMS
}

\author{
Maria Luskova \\ University of Žilina in Žilina, Faculty of Special Engineering, Žilina, Slovakia
}

\section{(C) MESTE NGO}

JEL category: L16, L22, 033

\begin{abstract}
The paper explores actual trends in integration of management systems which can help in solving the problems that some organizations face in the separated systems. A growing body of information indicates that organizations are increasingly implementing integrated management systems that bring them significant benefits. Contemporary trends aim at complex integration of management systems when some of the models compromises the quality of the management system. Environmental management system and occupational health and safety system can be completed by other organization management subsystems, e.g. risk management system, corporate social responsibility, energy management, etc. The degree of the management systems integration depends on the specific needs of an organization. Since the integration process is not standardized, each organization may apply its own methodology or the existing guidelines and standards. It is recommended to use the existing experiences of other organizations that successfully improve their integration process, or to contract a consultant for assistance. Except for many benefits, this integration approach can also bring some limitations that are related especially to a tendency to develop over-documented bureaucratic process and unwillingness of quality professionals to accept requirements that do not relate to product quality.
\end{abstract}

\section{Keywwords:}

management, management systems, integration, quality, environment, health, safety

\section{INTRODUCTION}

In the last years many organisations implemented or are implementing multiple management systems in light of increasing competitive pressure and effort to meet requirements of their internal and external stakeholders. Products supplied by the firms

The address of the author: Maria Luskova

麦"=" maria.luskova@fsi.uniza.sk have to meet demanding requirements of the customers and also must conform to the social requirements for protection of natural environment, health and safety and so to meet demanding requirements resulting from laws, regulations and also moral codex. Whereas in the past injuries of persons, damages and pollutions caused by defected products or services were not accepted as decisive matter, today the producer is legally responsible for these matters (Kmet', 1998). 
Organisations with implemented multiple management systems, that frequently are operated as independent systems, are considering, more and more, integrating their different management systems into a single system, because of its efficiency and exploitation of synergies (Bernardo, 2011). The problem is that the integration process is not standardized and each organisation must find a way how the processes within the management systems can be best integrated to achieve significant integration benefits and meet business needs. Integration of management systems requires to take into account a lot of aspects and therefore in case of a lack of knowledge it is recommended to study the methodologies proposed in the literature and use existing experiences of other organisations that successfully improve their integration process or contract a consultant for assistance. The aim of this paper is to provide a brief overview of the integration methodologies as well as benefits and limitations of integration that can serve as a starting point for designing integrated management systems.

\section{METHODOLOGIES PROPOSED BY STANDARDIZATION BODIES AND PROFESSIONAL BODY FOR QUALITY MANAGEMENT}

The effort to integrate requirements laid down in various international and industry standards in a single uniform management system has resulted in developing several standards or guidelines in different countries. They include:

\section{A. AS/NZS 4581:1999}

This Australian International Standard AS/NZS 4581:1999 Management System Integration Guidance to Business, defines integrated management system (IMS) as a consolidation of processes, procedures and practices used by an organisation to implement the policy of the organisation where the organisation will be more efficient in achieving the goals and policies from the management system which is different (Kadir, 2011). The common elements of the management systems as the quality, safety and health, and environment can be integrated into a single system, although other systems such as human resource management or financial control can also be integrated (Bernardo, 2011).
The main components of the IMS according to the AS/NZS 4581 are as follows (Kadir, 2011):

- Leadership \& Management Responsibilities. - Identification \& Analysis Requirements.

- Objectives \& Policy.

- System Design \& Implementation.

- Distribution Source.

- Communication \& Information.

- Resources.

- Process \& Management Activities.

- Measurement \& Monitoring.

- Re-evaluation Management \& Improvement Plan.

\section{B. PAS 99:2006}

The British standard PAS 99:2006 defines the common requirements of management systems. It is intended for use as a framework to implement the common requirements or specifications for an integrated management systems. The adoption of this standard allows simplifying deployment of multiple management systems. The particular requirements of each management system must be managed and satisfied to achieve certification and help for organisations to achieve the benefits of the consolidation of the common requirements. The standard specifies that integration must be planned and improved in a structured manner and adopted for internal benefits (Bernardo, 2011). The benefits include e.g. improved business focus, a more holistic approach to managing business risks, reduced duplication and bureaucracy. Although the PAS 99 was primarily intended to be used for ISO 9001, ISO 14001, ISO/IEC 27001, ISO 22000, ISO/IEC 20000, OHSAS 18001 it can also be used for other national and international management systems and specifications (PAS 99, 2006).

\section{UNE 66177:2005}

The Spanish standard UNE 66177:2005 (AENOR 2005) provides guidelines for developing, implementing and evaluating the integration of quality management systems, environment and health and safety at work. This standard helps the management team to design and implement an integrated management system and identify methods and tools applicable for the implementation of an integrated management 
system. It is based on the PDCA cycle of continuous improvement (Bernardo, 2011).

The Chartered Quality Institute (CQI) defines integrated management as the understanding and effective direction of every aspect of an organisation so that the needs and expectations of all stakeholders are equitably satisfied by the best use of all resources. According to CQI the integrated management is characterized as follows (Dalling, 2007):

- can be applied to any type or size of organisation (commercial, government, regulatory, etc.),

- should be holistic,

- should make no distinction in its general approach to managing potential loss and potential gain,

- leads to optimal efficiency (economic use of resources) and optimal effectiveness (meets objectives by satisfying the totality of stakeholders needs in an equitable way),

- should be inclusive - address the totality of the organisation and its stakeholders,

- should address the totality of stakeholder's needs and aspirations in an equitable way,

- must include every facet of management that may impact stakeholders such as health, safety, environment, ethics etc.,

should require that all components of an organisation add optimal value both individually and collectively,

- should take an approach embracing simplicity, least action, least use of energy, efficient and effective use of total resources

should address all aspects that contribute to an organisation's performance such as the process, management system, culture, knowledge base, top management leadership, stakeholders and human consciousness,

should require managers to recognise and take into account all significant influences on their organisation such as the strategic direction of the business, relevant legislation and standards, internal policies and culture, resource requirements and the needs of those who may be affected by any aspect of the organisation's operation or existence.

\section{DIMENSIONS OF THE INTEGRATION OF MANAGEMENT SYSTEMS}

Each organisation, in accordance with its own objectives, concentrates on satisfaction of the requirements of the five groups of its stakeholders that include staff, customers, suppliers and partners, owners and investors, neighbours and the public. Requirements of these stakeholders refer to work conditions, motivation, quality, service, reliability, value enhancement, risk management, environmental protection, etc.

When designing an IMS it is useful to break down it into several dimensions (Figure 1).

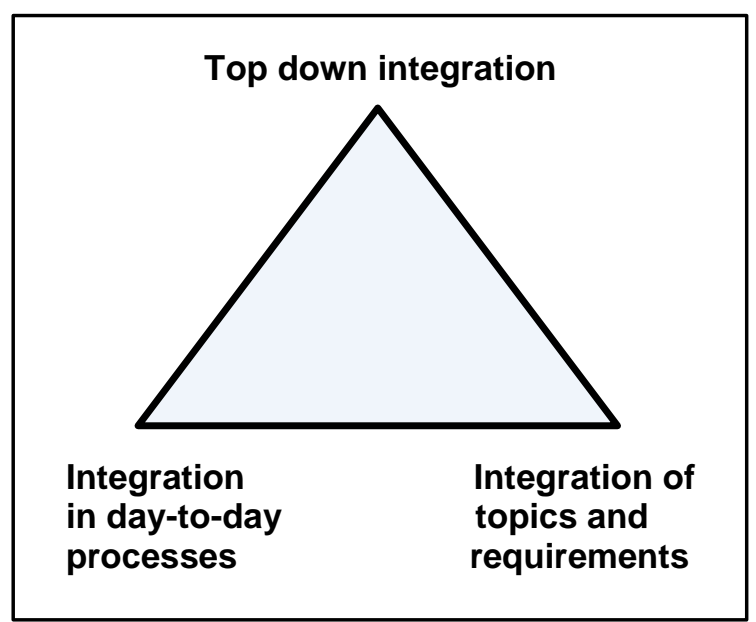

Fig. 1 Dimension of the integration of management systems (Quality Austria, 2012).

The top down integration is a basic requirement that means the organisation mission and strategy will be reflected in its processes since the value is added just through the best possible integration in the value -oriented processes. Integrated management system requires a consistent leadership framework that allows understanding the different requirements of the individual management systems and so to satisfy them in accordance with the organisation values.

The integration of topics and requirements is usually given the maximum priority when designing an IMS. The requirements of the 
individual stakeholders often correspond with the requirements resulting from standards. While in the past these requirements were perceived in an isolated manner, at present understanding the connections and interrelations of processes is required. This enables to integrate the different requirements and keep the documentation of the IMS simple, understandable, easy to amend and enhance.

The integration in day-to-day processes considers the fact that a lack of consistency is more probable in implementation than consistent practice. So the importance of the leadership tasks of implementation and enforcement becomes apparent. Rooting the management system in day-to-day processes brings alive and effective economic benefit (Quality Austria, 2012).

\section{APPROACHES TO INTEGRATING MANAGEMENT SYSTEMS}

At present the principle not to look at various but closely coherent systems as isolated and mutually independent systems is generally applied and the effort to put them on common base - modern management of processes is pursued. Based on the experience of people working with IMS, the following ten approaches to IMS have been defined (Quality Austria, 2012):

- Approach through stakeholders - ensures balance and reconciliation of interests. It is important to take into account the requirements and expectations of all stakeholders and to find an adequate balance. ISO 9004 approach to integration is based on the five stakeholders of employees, customers, owners, suppliers and society.

\section{Approach through strategy - consolidates the operating business. Top down integration should be consistent, target-oriented action in all important fields of organisation. Harmonisation and consistency of the targets down to the process and process indicator levels should be supported by the management system.}

- Approach through organisation - creates effective structures. Documents as organisational chart, jobs description, position descriptions, etc. and process model (structure) should be reviewed and supplemented by requirements from the models to be integrated.

- Approach through employees - fills a management system with life. The involvement of the staff, increasing their awareness of the IMS advantages, further development and the avoidance of discouragement are major factors of success.

- Approach through process managementprovides a basic framework for designing processes. The organisation process model forms the important basis for the integration of additional topics relating to the environment, safety, health, risk and further specific requirements.

- Approach through key performance indicators - makes effects measurable. It is important to put the key performance indicators into an appropriate context, process them together and to use them jointly for decision-making in the future.

- Approach through legal certainty- creates a court-proof organisation.

- Approach through rules and standards creates an overview and synergies. Overlapping requirements are worked on and documented only once in an integrated management system. So the regulations resulting from this process cover overlapping requirements and the overall system documentation is lean.

- Approach through documentation reduces effort and boosts acceptance. The aim is to create a single integrated, selfcontained set of rules for mapping several requirement models. Duplications and possible contradictions are identified and avoided.

- Approach through established methods makes successful implementation easier. Methods (PDCA, Q7, M7, 5S, FMEA ...) reduce complexity and support the visualisation of challenging situations and the decision - making process, taking into account all relevant aspects. It is important to have professional competence when working on a specific task. 
The degree of organisation management systems integration depends upon its specific needs. Each organisation should evaluate its applied management systems and then decide how the processes within those systems can be integrated to achieve the best results. Although the organisation is able to integrate the systems, the consultations with specialist to ensure that regulatory requirements are identified, met and continually improved are necessary.

\section{INTEGRATION OF QMS, EMS and OHSAS}

The Quality Management System, Environmental Management System and Occupational Health and Safety Management Systems are the most often combined and managed as an integrated management system. The above mentioned Australian International Standard AS/NZS 4581:1999 provides IMS model based on identification of common needs and unique requirements of each major management system (Fig. 2) (Kadir, 2011).

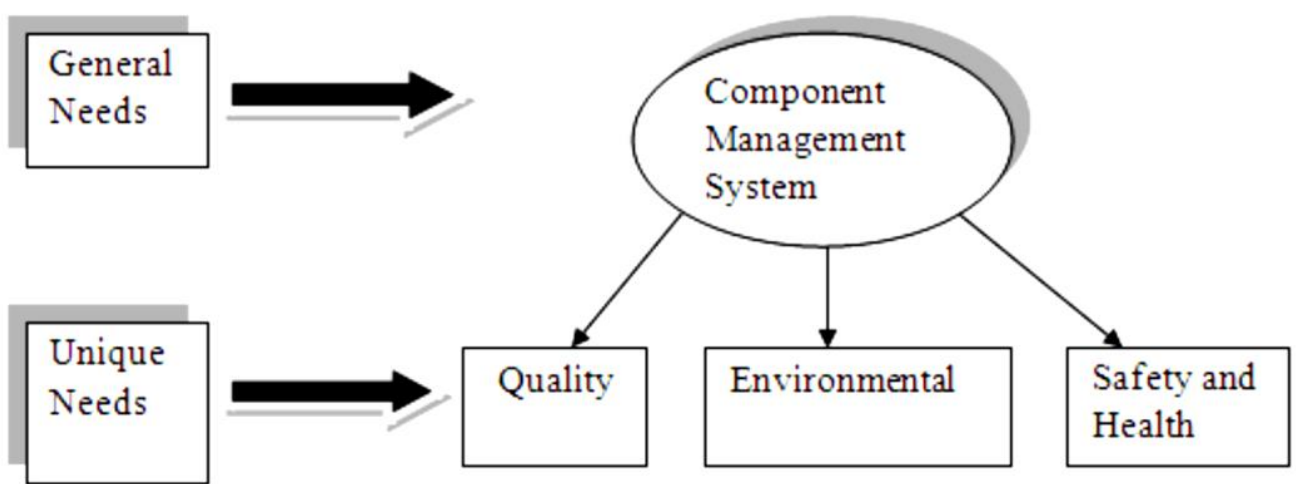

Fig. 2 Integrated management system model AS/NZS (Kadir, 2011).

The first compact field, where the management of the Slovak industrial enterprises has gained any experience, was the quality management system according to the ISO 9000 . This system has become necessary marketing-commercial condition and basic assumption of products and services saleability for the majority of the Slovak enterprises.

The ISO 9000 family of standards (1.version 1987) have their origin in the USA military standards. Within several years practically all industrial countries adopted these standards to their national systems. In 1994 so called "small revision" of the ISO 9000 was realized. The ISO 9000:1994 family of standards had universal character and in consequence of this the formulations were too general, uncertain and some especially beginning organisations were not able to master the application of the standards requirements into practice. They presented file of minimum requirements that should be implemented in organisations; the principle of continuous improving was missing. In 2000, the great principal revision of the ISO 9000 family of standards, that are based on the system access to quality and use of managerial methods and tools, was realized.

From the above mentioned follows that the system of ISO standards is constantly developing and enhancing and not only from the view of the range of including fields but also from the view of approaching to the other aspects of human activity, human needs and interests, e.g. safety and health protection, protection of natural and working environment, data protection and security, social responsibility of organisations, etc., that cannot be omitted at any level (Nenadál, 2008).

The greatest damages to natural ecosystems are caused by business sphere. In the past, many industrial enterprises did not feel directly the impacts of their negative acting on the natural environment and therefore they did not deal with these problems. Therefore it was necessary to force them to be active in the natural environment protection through legislative and environmental politics. At present, the organisations have to respect more and stricter requirements for natural environment protection including integrated prevention and control of pollution and a lot of 
legal regulations related to natural environment. The Environmental Management System (EMS) enables to master these tasks and also to obtain the competitive advantage.

At present two systems of environmental management are applied in Europe (Mateides, 2006):

- EMS (Environmental Management System) presented by the ISO 14000 family of standards that proceeds from ISO 9000 , it is concentrated not on the quality but on the impact of production and services on natural environment.

- EMAS (Eco-Management and Audit Scheme) based on the Council Regulation (EEC) No.1836/93.
OHSAS 18001 (Occupational Health and Safety Management System) is international standard that presents requirements for safety management system and occupational health protection, enables to manage relating risks and improve the organisation performance. OHSAS is applicable for each organisation that is going to certify the system of the safety and health protection at work (Veber, 2010).

Although the requirements of the above mentioned standards ISO 9000, ISO 14000 and normative recommendation OHSAS are different concerning their scope, their structure of requirements, processes for their implementation and maintenance are very near (Figure 3 ).

\section{Common requirements of ISO 9001, OHSAS 18001and ISO 14001}

Control of documents

Control of records

Planning IMS (IMS policy, IMS objectives)

Communication

Management review

Human resources - competence, training and awareness

Register of aspects, regulations and legislation

Operational control

Audits

Monitoring and measurement, metrology

Non conformances, corrective and preventive actions

\section{Fig. 3 Common requirements of ISO 9001, OHSAS18001 and ISO 14001}

From this follows that assurance of these requirements within integrated management system is less demanding especially from the view of costs in comparison with autonomous isolated systems. Integrated system involving requirements of standards ISO 9001, ISO 14001 and normative recommendation OHSAS 18001 is one of the most often introduced integrated management system. Deming model of continuous improvement PDCA, that presents the basic platform of all three above mentioned systems, brings the compatibility among their requirements and enables to synchronize the requirements of individual systems into one integrated management system (Veber, 2010).

From the view of actual trends the QMS, EMS a OHSAS systems are joined by other subsystems of organisation management, e.g. risk management system, data security system, energy management, corporate social 
responsibility and other systems necessary for assurance organisation competitiveness. Especially the importance of the risk management is going to increase considerably in the near future.

\section{BENEFITS AND LIMITATIONS TO INTEGRATING MANAGEMENT SYSTEMS}

Development towards the integration of management systems is required also by actual worldwide trends of organisation management. But there is no just one rule how to integrate the management systems. Each organisation has to consider the nature of its business when deciding how far the integration will be applied to bring the best results.

There are many benefits to integrating the organisation management systems that include (McDonald, 2003):

- Simplification of systems - employees use only one set of working instructions and so the confusion, resulting from the use of documents from different management systems that can be sometimes conflicted, is minimized.

- Optimized resources - if one system meets the requirements of all systems, then the resources for development, implementation and maintenance of one integrated system are minimized in comparison with resources required by separate systems.

- Improved organisational performance - a formal system, that helps to identify potential problems and risks, can reduce also costs associated with these risks.

- Integration of management systems objectives into the overall business strategy this fact indicates the importance of the effective complex organisation integration as a base for the organisation competitiveness.

- Established framework for continual improvement of the integrated management system- the goals and objectives of the IMS are reviewed at the regular intervals, necessary corrective and preventive measures are accepted and also the opportunities are defined. This results in improved organisation performance.
There are also limitations to integrating the organisation management systems that include (McDonald, 2003):

- A tendency to develop over-documented bureaucratic processes - it is necessary to avoid writing uselessly lengthy procedures and working instructions that "do not let the people do their business".

- Turf battles - if the QMS already exists in the organisation, professionals from other fields often resist tackling their requirements onto the existing QMS. And likewise, the quality professionals do not like requirements in their system that do not relate to quality.

- Limits on degree of integration - some management systems are highly compatible, but requirements of some of them is not possible to integrate with existing quality system easily.

\section{CONCLUSIONS}

The integration of management systems is a very important tool to reduce the complexity of an organisation management system and provides an opportunity to manage organisations more effectively and efficiently. Integrated management systems implementation has become an important issue of organisation competitiveness and sustainability. Therefore many integrated management activities are either being planning, underway or have been completed within the companies.

From the literature review as well as experiences of organisations that have successfully undertaken the integration of their management systems results that development and implementation of integrated management systems require careful preparation as there are number of challenges and barriers accompanied by integration. They include, e.g. people's attitudes to changes, communication gaps between the top-middle management and employees, lack of qualified personnel, very high fees charged by consultants and their participation in maintaining the integrated systems, updating the systems due to continually changing regulations and guidelines, ensuring a fast reporting system across the organisation to avoid delays in the finalisation of the future 
improvement plans, possible time-delays of some departments in integration that should be considered when finalising the target dates (Zutshi, 2005).

Smoother and faster course of integration of management systems can be achieved through these recommendations (Zutshi, 2005, Dalling 2012 ):

- Top management commitment and management review - top management support and commitment is essential for the integration process to be initiated, completed and mainted within the organisation. Regularly held management review dealing also with results of the internal audits and the overall direction of the company is important for the maintenance and progress of the system.

- Appointing a representative from the management responsible for successful implementation and maintenance of the integrated system. Such person must be a good communicator, negotiator, coach and trainer.

- Adequate training for all employees - the training program should be aimed to provide employee's awareness of the need and benefits of an integrated system and understanding the way of its implementation, utilisation and maintenance.
- Maintenance and control of documentation system to avoid duplication of procedures and confusion among the employees.

- Regular reliable internal and external audits of all management systems carried out by multidisciplinary team. Integrated audits save resources and help to obtain holistic view of the necessary improvements.

- Building the organisation culture that is willing to embrace change and people are avoiding clashes.

- Educating and closely working with the suppliers.

- Communication is the most effective way to overcome the problems and demanding tasks.

Integrated view of management systems is supported also by the International Organisation for Standardisation (ISO). The ISO members have made considerable progress in the harmonisation of texts and standards structures what leads to the holistic concepts in organisation management e.g. context of organisation, leadership. It is expected that in the future the organisations will be able to meet all requirements only through a single comprehensive integrated management system that will contribute to the organisation success.

\section{Works Cited}

Bernardo,M., Casadesus,M., Karapetrovic,S. (2011) ARE METHODS USED TO INTEGRATE STANDARDIZED MANAGEMENT SYSTEMS A CONDITIONING FACTOR OF THE LEVEL OF INTEGRATION? In: International Journal for Quality research. Vol.5, No. 3, 2011. [online]. [cited 12 September 2012]. Available at: http://www.thecqi.org/Documents/community/IM\%20SIG/CQI\%20IMSIG\%20Integrated\%20ma nagement\%20definition\%20-\%20lssue\%202.1.pdf http://www.ijqr.net/journal/v5-n3/7.pdf

Dalling, I. (2007) Integrated management Definition. In: CQI IMSIG - Integrated Management Definition - Issue 2.1 - 11/05/2007 [online]. [cited 12 September 2012]. Available at: http://www.thecqi.org/Documents/community/IM\%20SIG/CQI\%20IMSIG\%20Integrated\%20ma nagement\%20definition\%20-\%20lssue\%202.1.pdf

Kadir, A. et al. (2011) Integrated management system: Readiness business organisation s in Malaysia. In: Journal of Food, Agriculture \& Environment Vol.9 (1): $745-750.2011$. [online]. [cited 12 September 2012]. Available at: http://www.isfae.org/scientficjournal/2011/issue1/pdf/environment/60.pdf

Kmet',S. et al. (1998). Komplexný manažment kvality. Žilina: EDIS - Vydavatel'stvo Žilinskej univerzity, 1998. ISBN 80-7100-562-2

Mateides, A. et al. (2006). Manažérstvo kvality. Bratislava: Ing. Miroslav Mračko, 2006. ISBN 80-8057656-4 
McDonald, M., Mors, T., Philips: A. (2003). Management System Integration: Can it be done? In: Quality Progress. October 2003. ISSN: 0033-524X.

Nenadál, J. et al. (2008). Moderní management jakosti. Praha: Management Press, s.r.o., 2008. ISBN 978 - 80-7261-186-7

PAS 99:2006 Specification of common management systems as a framework for integration. BSI 2006. ISBN 0580490599

Quality Austria. (2012). Integrated Management Systems The Position of Quality Austria. Edition 02/2012 [online]. [cited 17March 2012]. Available at: http://www.qualityaustria.com/

Veber, J. et al. (2010). Management kvality, environmentu a bezpečnosti práce. Praha: Management Press, s.r.o., 2010. ISBN 978- 80-7261-210-9

Zutshi, A., Sohal, A. (2005). Integrated management system: The experiences of three Australian organisations. Journal of Manufacturing Technology Management, Vol.16 Iss:2 pp. 211-232

This paper was elaborated within the project

KEGA 077žU-4/2011 Integration of Quality and Risk Management.

\section{How to cite this article?}

Style - APA Sixth Edition:

Luskova, M. (2013, 07 15). The contemporary trends in integration of management systems. (Z.

Čekerevac, Ed.) MEST Journal, 1(2), 71-79. doi:10.12709/mest.01.01.02.06

Style - Chicago Fifteenth Edition:

Luskova, Maria. "The contemporary trends in integration of management systems." Edited by Zoran Čekerevac. MEST Journal (MESTE) 1, no. 2 (07 2013): 71-79.

Style - GOST Name Sort:

Luskova Maria The contemporary trends in integration of management systems [Journal] $=$ Trends in integration of management systems // MEST Journal / ed. Čekerevac Zoran. - Belgrade : MESTE, 07 15, 2013. - 2 : Vol. 1. - pp. 71-79. - ISSN 2334-7058 (Online); ISSN 2334-7171.

Style - Harvard Anglia:

Luskova, M., 2013. The contemporary trends in integration of management systems. MEST Journal, $1507,1(2)$, pp. 71-79.

Style - ISO 690 Numerical Reference:

The contemporary trends in integration of management systems. Luskova, Maria. [ed.] Zoran

Čekerevac. 2, Belgrade : MESTE, 07 15, 2013, MEST Journal, Vol. 1, pp. 71-79. ISSN 2334-7058

(Online); ISSN 2334-7171. 